\title{
Varijacije, odjeci i tragovi matoševskog flanerizma u izboru iz suvremene hrvatske proze
}

\begin{abstract}
Gajin Igor, Varijacije, odjeci i tragovi matoševskog flanerizma u izboru iz suvremene hrvatske proze (Variations, Reverbaration and Traces of Matoš's flâneurism in the Selection of Contemporary Croatian Prose). „Poznańskie Studia Slawistyczne” 7. Poznań 2014. Publishing House Science and Innovate, pp. 107-118. ISBN 978-83-63795-79-5. ISSN 2084-3011.

In his book, Čitanje grada (Reading the City), Krešimir Nemec stated that A.G. Matoš has „,modeled after Baudelaire, introduced to the Croatian literature a figure of an idle observer, a curious pedestrian or a flâneur, a typical impressionist product of urban culture and aesthetics of the street". As a reference and a starting point for reflection on flâneurism's motifs in contemporary Croatian literature, A.G. Matoš is used as a factor of distinction in outlining one of the most characteristic aspects of the so-called transitional literature. Having said that, a common conclusion is that flaneurism has, in the Croatian contemporary prose, moved from the streets to the shopping malls. However, contemporary Croatian prose offers the reading of other flâneurism practices as a movement that reflects the changes in categories of urban life, space, daily life and discourse in the transition period from the $20^{\text {th }}$ to the $21^{\text {st }}$ century due to the transformative processes such as a transition, globalization and media revolution. Ultimately, Nemec writes: „If he had experienced the present era of electronics and virtual reality, Matoš probably would have called the tireless surfers of the endless Internet sphere electronic flâneurs".
\end{abstract}

Keywords: flâneurism; transition; postmodernism; mediasphere; strategies; trajectories

\section{Uvod}

Miroslav Krleža u jednoj se od svojih esejističko-dnevničkih bilješki pita: „Što je ostalo od A.G.M.; kao Škole?” (Krleža 2013: 112) te 
rezignirano konstatira da je od Matoševe grabancijaške, dakle boemske i lutalačke lirike, ostalo tek „nekoliko fraza”, „,nekoliko stihova”. Iako je Krleža tu dvojbenu misao zabilježio ukratko, u fragmentu, možda kao natuknicu i skiciranu tezu za neki budući, opsežniji tekst o ideji koju je tako, za prvu ruku, jednopotezno registrirao, zaključak je već upisan. Naime, prema Krležinu sudu, Matoš nije samo osamljena figura na hrvatskoj književnoj sceni bez srodnika u sinkronijskoj galeriji, nego i bez nasljednika: sve matoševsko prestaje s Matošem i baš ništa od spisateljske prakse toga hrvatskog književnika ne biva upisano u rukopise sljedećih književnih naraštaja. Štoviše, Krleža fatalistički dodaje da nikad neće ni biti.

Ipak, danas nipošto nije uzaludno ponirati između redaka suvremenoga hrvatskog književnog pisma radi prepoznavanja, pronalaženja odjeka matoševske misli i tragova matoševskog naslijeđa kada je riječ o stilu, esteticizmu, polemičarskim strategijama, patriotizmu, doživljaju provincijalnog usuda. Tim više što je opus Antuna Gustava Matoša kao lektirski uvjetovano štivo vjerojatno bilo u rukama baš svakoga suvremenog hrvatskog pisca, pa se stoga izravno ili neizravno upisalo u mozaik iskustava i kolektivnu kulturnu memoriju autorskih subjekata na aktualnoj hrvatskoj književnoj sceni. Iz mreže mogućih, (ne)hotimičnih doticaja i dijaloga, korespondiranja i bratimljenja u naslovima suvremenih hrvatskih književnika s plodovima Matoševa autorstva opredjeljujem se za utvrđivanje jednog aspekta tog kontinuiteta praćenjem razvojne linije kojom se kretao motiv flanerizma od Matoša do današnje hrvatske književnosti, pri tome se skromno upisujući između dviju rečenica Krešimira Nemeca iz knjige Čitanje grada.

On, naime, s jedne strane zapisuje: „Matoš je po uzoru na Baudelairea uveo u hrvatsku književnost figuru dokoličara-promatrača, radoznalog šetača ili flâneura, tipično impresionistički proizvod urbane kulture i estetike ulice” (Nemec 2010: 75), dok s druge strane navodi: „Da je doživio današnje vrijeme elektronike i virtualne zbilje, Matoš bi vjerojatno i neumorne «surfere» po bespućima interneta nazvao «elektroničkim flâneurima»" (Nemec 2010: 86-87). Drugim riječima, ono što je u hrvatskome književnom stvaralaštvu nominalno otpočelo s Matošem, dakle flanerizam, kroz povijest novije hrvatske književnosti nastavilo je biti ispisivano, znakovito bivajući od etape do etape transformirano ili parafrazirano. Tako danas imamo flanerističku praksu i flanerističke motive u suvremenoj hrvatskoj prozi čija odstupanja u odnosu na inicijalni tip flanerije kakav je uveo Matoš reflektiraju 
fundamentalne promjene u kategorijama urbanosti, svakodnevice, društvenog poretka i njegove diskurzivne reprezentacije, tekstualnog otiska aktualne zbilje, ujedno nam poručujući iz te razlike u gramatici prostora manifestirane u tekstu simptomatične signale i konstatacije vremena u kojem živimo.

Čitati mijene flanerije njenim putem u tekstu hrvatske književnosti ne znači samo evidentirati povijest jednoga znaka u dijakronijskom presjeku da bi se reklo i shvatilo nešto više o književnosti samoj, nego se iščitavanjem flanerizma i zapažanjem naglašenije znakovne vrijednosti karakteristično biranih adresa i punktova flanerije dešifrira tako ispisana i projicirana zbilja u tekstu kao mozaičan doprinos ili otpor aktualnoj paradigmi. Još će Walter Benjamin, sažima Danko Grlić, u Badeulairevoj flaneriji prepoznati novi tip umjetnika, umjetnika na prijelazu iz mecenatskoga u kapitalističko tretiranje umjetnosti, umjetnika u repozicioniranju, traženju uloge u novonastaloj strukturi odnosa (Grlić 1984: 35), dok će sâm Benjamin jedan vid flanerije smjestiti ,između sivog kamenja pločnika i na sivoj pozadini despotizma" (Benjamin 1986: 45).

\section{Kako je Walmart zamijenio Montmartre}

U Matoševu doživljaju flanerizma kao da nema primisli na ovu tešku ideološku pozadinu spomenutu uz Benjamina i Grlića. Iako je i u njegovoj praksi flanerije prisutan egzistencijalistički razlog (Nemec 2010: 77), i doista je zbog opskurnih podstanarskih ćumeza prinuđen eksterijer pretvoriti u svoj interijer (Benjamin 1986: 45), ipak preteže estetizirani, odnosno afirmativan doživljaj: ,flâneur je umjetnik, svrha mu je flaniranje - l'art pour l'art" (Matoš 1988: 90). Za njega flanerija nije izričito subverzija, a flaner nije lutalica koji „u svojoj ostentativnoj egzistenciji u prolazu protestira protiv samog procesa proizvodnje i njegovih konzekvencija na tržištu" (Grlić 1984: 35), nego je na neki način posljednji prostor aristokratskog luksuza u mogućnosti neopterećenog, neokaljanog i u potpunosti posvećenog življenja apsolutne ljepote i slobode. Na kraju krajeva, Matošu su idealni flaneri - oblaci. Premda se vrijednosti koje Matoš pripisuje flaneriji mogu čitati kao implicitna poruka upućena vulgarnosti i utilitarnosti kapitalističkog diktata umjetnosti (kao i profane egzistencije općenito) na tragu Benjaminovih i Grlićevih razmatranja, ipak treba uzeti u obzir da je 
Matoševo oduševljenje modernom mobilnošću, ne samo ljudi nego i trgovine i kapitala, izazvano dojmom da mu ta dinamika ide u prilog, kao potvrđivanje njegovih uvjerenja, čak do te mjere da konstatira kako trenutne tendencije pokazuju da je cilj kulture flanerski. Ako i jest, tj. ako je Matoš i bio u pravu, danas se time ne oduševljavamo, posebice ako govorimo riječima Zygmunta Baumana o posljedicama obestjelovljenja rada i eksteritorijalnosti kapitala, njegovu bestežinskom stanju. I za Baumana su kapitalisti oblaci, ali u negativnom smislu: oni bi ,radije razmijenili masivne uredske zgrade za kabine u balonu na vrući zrak” (Bauman 2011: 120).

Pojasnimo eventualno zakomplicirano: za Matoša flanerija nije sredstvo otpora, nego medij uživanja; njegov odgovor ili, točnije rečeno, prepuštanje dinamičnoj mnoštvenosti urbane ponude od senzacije do senzacije.

U svakom slučaju, počev od Matoševe flanerije, hrvatska će književnost postupno doći do maloprije rečenoga, zadržavajući od matoševske flanerije tek ideal (ili s vremenom sve više tek iluziju) slobode, otprilike onako kako to demonstrira hrvatski književnik Damir Karakaš u autobiografskom romanu Sjajno mjesto za nesreću. Opisujući šetnju Parizom, Karakašev lik šumu (doslovno šumu, a ne park) usred urbane konglomerije otkriva s čuđenjem i oduševljenjem, doživljavajući je poput praznika, rijetkog i dragocjenog trenutka predaha i bijega od tempa suvremenog društva i gradske klaustrofobije. No primijetit će potom nešto bajkovito crveno u gustišu šume, da bi shvatio kako je riječ o - McDonald'su! (Karakaš 2009: 102).

Damir Karakaš suvremeni je hrvatski prozni autor koji najizravnije ispisuje posvetu Matoševu liku i djelu, eksplicitno navodeći u svojim prozama da mu snagu za tegoban boravak u Francuskoj uveliko daje Matoševa biografija te neskriveno pridonosi veličanju mita o boemskim danima A.G.M-a u Parizu. Ipak, Karakaševo bezrezervno zanošenje Matošem nije bez nadgradnje, zanimljive inovacije koja donosi novi moment u tradiciji flanerizma ispisivanoga u hrvatskoj prozi. U romanu Kako sam ušao u Europu Karakaš opisuje iskustvo preživljavanja u Francuskoj zarađivanjem kao ulični svirač i karikaturist, smještajući se opredijeljenjem za takvu pripovjedačku perspektivu u objekt flanerizma, bivajući tek jednim od sadržaja i atrakcija ulične ponude za mnoštvo flanera sjaćenih u Pariz iz svih dijelova svijeta. Jasno, inovacija je u tom obratu, u tom rotiranju tradicionalne pozicije iz koje se ispisuje tzv. flaneristički žanr: flaner više nije subjekt, ponekad i prejaki subjekt koji objekte (ili, točnije rečeno, impulse) svojim 
flanerističkim senzacijama zamagljuje prakticirajući naglašeni subjektivizam i postupno te objekte, kao iskorištene ljubavnice, potiskuje u duboku pozadinu poradi daljnjih asocijacija i doživljaja koji se nižu tekstom autonomnim tijekom. Naprotiv, u ovom slučaju, flaneri su detronizirani, oni su objekti, i to vrlo kritički tretirani objekti, anonimna masa. Dok flaner prividno spoznaje objekt portretirajući ga nadugačkom retorikom svojih impresija i mišljenja, flaneristički objekti su s Karakašem dobili svoj glas.

Kada je riječ o hrvatskom književniku Edi Popoviću, autoru koji radikalno mijenja poziciju, gotovo za 180 stupnjeva, dva su njegova romana glede istih motiva u kontrapunktu zbog paradigmatske promjene društveno-povijesnih okolnosti. S jedne je strane tog kontrapunkta Popovićev Ponoćni boogie iz 1987. godine u kojem rokerski protagonist boemski flanira gradom, suvereno se krečući tim prostorom i doživljavajući ga prilično erotizirano, neopterećno prepušten nepredvidljivostima i slučajnostima, tj. iskrslim birtijama, ljubavnim avanturama, neplaniranim pijanstvima i snošajima, veličajući prostor grada kao prostor slobode i tretirajući svoj doživljaj prema gradu gotovo koitalno. Godine 2011. taj isti pisac objavljuje i roman Lomljenje vjetra u kojem je grad u potpunosti koloniziran kapitalom te korporativno-proizvođačkom i šopingholičarsko-potrošačkom filozofijom, tako da za beskorisne flanere tu nema mjesta. Status flanerije kod istog se autora u roku od nekoliko desetljeća mijenja, potpuno u duhu podjele na laku i tešku postmodernu, zaigranu i političnu (Oraić Tolić 2005: 43), u skladu s mijenom iz dekadentne faze vedrijeg socijalizma u divljaštvo tranzicijskog i neoliberalnog kapitalizma, pa Popovićev junak iz hedonistički vođene flanerije zapada u flaneriju koja je uzrokovana socijalnom tragedijom. U kontekstu tranzicijske drame flanirati, odnosno biti na ulici, više nije stvar gordog otpora prema institucionalnim uprezanjima i ukalupljivanjima prema diktatima sustava, nego poniženje, rezultat besposlenosti i besparice. Flaniranje se svodi na traganje za otpacima u kontejnerima, a jedan će od likova u Lomljenju vjetra reći: „I ja sam na ulici, osjećam se k’o zadnje smeće" (Popović 2011: 82).

Taj je tranzicijski obrat u tradiciji flanerije kroz tekst hrvatske suvremene proze ekstenzivnije popisala i usustavila Maša Kolanović (Kolanović 2008: 69-89), izvrsno kartografirajući u nizu hrvatskih proznih djela flanerističku putanju koja je ili disciplinirana tehnikama sustava ili kojom se ispisuje taktika otpora prema dominantnom poretku sa znakovitom sklonosti flanera 
prema punktovima i prostorima potencijalne subverzije ili pasivne opozicije, kao što su: periferija, margina, kvart (u opreci prema centru kao epicentru proklamiranih vrijednosti sustava), kafić/birtija, ali i trgovački centri, tj. hramovi kapitalističke ideologije koji se „podrivaju” nerealiziranjem trgovine, pukim šetanjem među policama i razgledavanjem.

Tom nizu u pregledu suvremene hrvatske proze iz istraživačkog kuta Maše Kolanović dodao bih još dva autora, ne zato što ih smatram previđenima, nego zato što naizgled netipičnu poziciju subjekta u njihovim prozama pronalazim također nadopisanom na nit flanerističke prakse kao novi moment, povrh konvencionalnog percipiranja realizacije flanerističkog motiva u tekstu hrvatske književosti, kao imaginiranje prostora književnim jezikom te kao simboličku sliku, pa čak i preslik koji je u dijalogu ili polemici s izvanknjiževnim prostorom društvene i ideološke zbilje. Odnosno, zapažena se flanerija u tekstu uobičajeno pripisuje doslovnom kretanju protagonista umjetnički konstruiranim prostorom, najčešće gradom ili urbanim pejzažem, pa se, budući da se smatra kazivanjem (ili, recimo to tako, pisanje nogom), iščitava mapa te flanerije, znakovni niz čija se semantika, gramatika i ideologija dešifriraju kao izraz ili refleks strukture osjećaja, a njen trag označenim, kao diskurzivna artikulacija zbilje.

\section{Migracija u simboličko polje kulture, virtualnost i medijasferu}

Riječ je o romanu Dobro je, lijepo je Ivice Prtenjače iz 2006. godine te o romanima Krešimira Pintarića Ljubav je sve iz 2005. i U tvom zagrljaju zaboravljam svako pretrpljeno zlo iz 2008. godine, djelima koja su uz zbirku priča $U$ što se zaljubljujemo Romana Simića uglavnom iščitavana kao val nove muške osjećajnosti, no ujedno su i djela čija se jedna znakovita zajednička karakteristika dosad uglavnom nije problematizirala, premda je riječ o indikativnoj poruci vremenu u kojem živimo. Naime, Prtenjačini, a posebice Pintarićevi protagonisti uopće ne izlaze iz stana.

„Ne damo se lako izvući iz kuće. (...) kako bi nam se uopće negdje išlo? (...) Kome treba izlazak, potencijalna pustolovina neizvjesnog ishoda...?”, pita se K. Pintarić (2005: 33). Najdulji izlazak njegova lika je - na balkon. Grad inače promatra kroz prozor, uvijek ga u kratkoj crti opisujući kao nešto sivo, neprivlačno, vizuru uspoređuje s dekorom filma Blade Runner 
(Pintarić 2005: 99), a susjede i prolaznike pod prozorom s određenom dozom mizantropije. Pintarićevo je konzumiranje urbanog prostora prinudno, na relaciji posao - stan; na poslu se provodi u dnevnoj smjeni, od jutra do predvečerja, a u stanu u noćnoj smjeni, uslijed egzistencijalne pritisnutosti ratama stambenog kredita.

Prtenjačin protagonist doseljava iz Rijeke u Zagreb zbog bijega iz provincije i prilike bavljenja poslom koji je bliži njegovu senzibilitetu (rad u knjižari, posao okružen knjigama). Flaneriju u Rijeci opisuje gotovo kao zatvorske šetnje, deprimirano zaključujući kako će se u tom očajnom krugu na kraju svatko sa svakim izredati u smislu ljubavnih i seksualnih veza. Flanerija u Zagrebu je prinudna, zbog viška slobodnog vremena nakon posla i zbog nenaviknutosti na unajmljeni stan, no osjećaj samoće i otuđenosti jednak je i kada boravi u stanu i kada kruži Zagrebom. Jede i pije vani, ali ga to ispunjava tugom, a okolinu također komentira mizantropski, pa na kraju rado odlučuje raditi dvostruku smjenu, odnosno cijeli dan (pri čemu je znakovito da je, dakle, radno mjesto prožeto toplinom doma, a stan i grad obilježeni su negativnošću i prazninom).

Ono što je ključno jest to da dok kod Pintarića već od prvih stranica imamo naizgled jasnu afirmaciju stambenog prostora kao skloništa, oaze, kao mjesto bijega, povlačenja, izmicanja, predaha, nenadziranosti i znakovite izolacije, ali i kao fetišizirani prostor samorealizacije i ispunjenosti, kod Prtenjače, nakon početne izjednačenosti otužnog stanja praznine unutra i vani, stan kao privilegirani prostor trijumfira na kraju romana. Proživjevši ljubavnu vezu sa susjedom, Prtenjačin protagonist na kraju zaključuje: „Ema je svojim noćnim izletima od mene učinila čovjeka koji se više ne boji stana u Ulici Side Košutić na broju 6" (Prtenjača 2006: 142).

Iako su navedeni romani pisani humorističnim stilom, tako da čitatelju nerijetko izazivaju osmijeh na licu, ukazani aspekti sugeriraju da je riječ o samo naizgled light kronici jednoga teškog i mučnog društvenog realiteta u pozadini. Čitamo li navedene naslove u ključu postmoderne poetike, odnosno kao simpatičnu potvrdu vrijednosti tzv. malih priča i nužne svedenosti nekad epske uzvišenosti umjetnosti na mjeru trivijalnih epizoda svakodnevice, nije na odmet imati na umu misao Rastka Močnika: „Uzmimo frazu da je nastupio «kraj velikih priča». Strategija je presudna. Najprije taj «kraj» vrijedi samo za moguće alternativne priče. One vladajuće ni ne treba pripovijedati, uspostavljena struktura cijedi ih sama od sebe" (Močnik 
1999: 32). I Prtenjača i Pintarić tu pobjedničku veliku priču, priču neoliberalnog kapitalizma, na trenutke eksplicitno izriču ili tematiziraju na površini svojih rukopisa, ali uglavnom je ona podrazumijevani kontekst zbog kojega je sve kako jest u njihovim romanima jasno i smisleno. Drugim riječima, nije iznenađujuće da rade od jutra do mraka, a navečer se zatupljuju televizijskim programom. U određenim trenucima njihovi protagonisti postaju bezrezervni glasnogovornici tog poretka, pa će Prtenjača zapisati: „Koliko je besposlenih ljudi, koji se klatare (...), ja žurim na posao. Oni mi samo smetaju” (Prtenjača 2006: 8), dok će Pintarić kroz dijalog reći: „Radiš cijeli dan, dođeš kući, malo se središ i onda uveneš od umora. I sutra opet tako. Pitaš li se ikad čemu sve to?”, na što će njegova djevojka odgovoriti: „Nemam vremena za razmišljanje, moram zarađivati” (Pintarić 2008: 25). Dakako, u tom je smislu heterotopijski karakter njihovih stanova, prostora realizirane utopije, tek samo iluzija jer se ni tu ne uspijeva uteći ulogama poretka. U stanovima, oni su konzumenti, potrošači, a eventualni kritički odmak i svijest o funkcioniranju sustava postideološki su cinični, što je najbolje ogledano u raspravi koju Pintarićev lik i njegova djevojka vode o porijeklu predmeta koje su kupili, odnosno o činjenici da su ih izradila potplaćena djeca Trećeg svijeta (Pintarić 2005: 124). Iz toga se ispostavlja da stanove u spomenutim djelima ne treba čitati kao posljednju liniju autonomije pred sustavom, nego naprotiv, kao prilično subverzivnu poruku zatočenosti: u stanu se odmara od cjelodnevnog rada i iz stana se ne izlazi jer je to najjeftinije - zarađeno odlazi na otplatu kreditnog duga.

Ukoliko nije riječ o discipliniranom flaniranju u smislu shoppinga ili o prinudnom flaniranju iz očaja odbačenosti, kao kod Popovića i dijelom kod Prtenjače, ili o flaniranju kao „tihom otporu na razini svakodnevice” (Kolanović 2008: 86), onda drugog flaniranja u hrvatskoj tranzicijskoj prozi - reklo bi se - i nema, posebice ako ćemo spomenute proze Pintarića i Prtenjače tretirati kao promociju statičnosti, učahurenosti, samodostatnosti u mikrouniverzumu postmoderne narcisoidnosti, odnosno kao proze u kojima flanerija izostaje, ili je jedva, slučajno prakticirana ili je negativno tretirana.

Međutim, treba uzeti u obzir da se u Pintarićevu i Prtenjačinu slučaju flanerija zbiva - nazovimo to tako - u drugom koordinatnom sustavu. Oni prvenstveno flaniraju pejzažem medijasfere i kulturne industrije: od knjige do knjige, od CD-a do CD-a, od linka do linka na internetu, od televizijskog 
kanala do kanala. Subotom uvečer, dakle u tradicionalnom terminu za izlazak u grad, flaniranje i ,ponoćni boogie”, Pintarićev lik čita Michela Houellebecqa i nabasa (!) na odlomak koji na njega djeluje epifanijski, ujedno bivajući i idejnom poentom romana. Zbog glazbe stan postaje duhovni prostor, crkva: ,ja sam prilično tvrdoglav, gotovo zadrt, kad je u pitanju akustika sobe koja ima, između ostalog, funkciju slušaonice!"' (Pintarić 2008: 31). Nadalje: ,sigurno ne slušam svih svojih 300 CD-a. U svakom slučaju, mislim da imam pravo reći da ta glazba i ja imamo prisan odnos, a ponekad nas vežu i prave male pustolovine" (Pintarić 2005: 122), navodi Pintarić, pri čemu treba podcrtati riječ pustolovina, riječ koja se veže i uz flanerističku praksu.

U nastavku praćenja ovakve vrste flanerije vrijedi zamijetiti i kontrast u razlozima „surfanja” u Pintarićevoj prozi: doma se „surfa” ciljano, radi informiranja uoči nabavke (namještaja ili akustičke opreme), a na poslu se krade vrijeme praćenjem internetskog trasha (što je diskretna bilješka o flanerističkom izmicanju, podrivanju i tihom otporu diktatu sustava). Televizija je u ovoj konstelaciji otvoreno najprezreniji medij flaniranja zbog banalnosti komercijalnih sadržaja i vulgarnosti masovne kulture, ali je ujedno paralelnost s karakteristikama flaniranja (tumaranje, slučajnost, nepredvidljivost, dokonost) najočiglednija: tijekom zappinga uvijek iskrsne neki prizor koji potakne doživljaj, reakciju, komentar. Urbani pejzaž kao izvor senzacija zamijenjen je telepejzažem. Multimedijalna infrastruktura stana omogućava virtualno flaniranje: „U stanu istovremeno radi televizor i radio (...). Napipam ono što volim" (Prtenjača 2006: 50).

I Pintarić i Prtenjača dovode virtualnu dimenziju, medijasferu i kulturni pejzaž u ravnopravan status s konstruiranim prostorom u tekstu koji bi mimetički bio ekvivalentan konvencionalno poimanom trodimenzionalnom, fizičkom prostoru materijalne zbilje. Pintarić će staviti znak jednakosti između doslovnog shoppinga i flaniranja Ikeinim i Kerumovim promotivnim katalogom nazivajući to „,imaginarnom kupovinom” (Pintarić 2005: 35), dok će Prtenjača prilično snažno oprimjeriti tu koegzistenciju i isprepletenost dviju mogućih dimenzija flaniranja: „Vozeći jedne noći ravno u Ramo$n u$, zastao sam uz more, privukao me snimljeni intervju Jacksona Pollocka s jedne američke stanice..." (Prtenjača 2006: 63). 


\section{Zaključak}

Vratimo li se na Matoša, među njegovim redcima nalazimo širok prostor za imenovanje svega i svačega flanerijom jer je egzaltirano doživljavao svaki vid kretanja kao potvrdu i afirmaciju flanerističkog ideala kulture: od krvotoka u ljudskom organizmu do kruženja nebeskih tijela, uključujući gibanje baš svega u tom dijapazonu.

Međutim: ,pojam flâneura čvrsto je vezan uz grad, urbanu scenu i arhitekturu" (Nemec 2010: 85). Nemec također dodaje da Matoš ne robuje tom ograničenju, nego ,još više razmiče granice” (Nemec 2010: 86) flanerije, stoga na tragu Matoševe širine prema shvaćanju flanerije ne vidim razlog da se nove prakse flanerije, flanerije 21 . stoljeća, ne prihvate kao inverzni i ravnopravni oblik tradicionalnog flaniranja, oblik u kojemu se sadržaji medijasfere i prostranstva kulturne industrije pridružuju kao prošireni prostori lutanja i estetskog užitka urbanim pejzažem.

Rastavimo li formulu flaniranja na proste faktore, proizlazi da jednadžba flaniranja glasi: intelektualno-estetski doživljaj/grad + kretanje, tj. da je flaniranje duhovni proces u kojem je duh osvježavan i obogaćivan zbrojem, udruženošću stimulativnih senzacija urbanog krajolika s poticajnošću koja proizlazi iz peripatetičkog učinka na dinamiku duha. Flanerije kod Pintarića i Prtenjače nema ako naglasak stavljamo na „fizičko” kretanje gradom i njegovim znakovitim punktovima (trgovački centri, kafići, periferija, kvart) kao obvezujući uvjet prepoznavanja i imenovanja subjektovih pozicija u tekstu flanerijom, no ako težište premjestimo na svrhu flanerije, po kojoj je ,grad često poticaj i polazište za čisto mentalne procese (Thum 1994: 22, prema: Nemec 2010: 81), odabire se određena «lokacija», a potom se oko nje plete «priča» u kojoj dolazi do izražaja feljtonistova erudicija i njegovo umijeće" (Nemec 2010: 81), onda možemo konstatirati da isti učinak umjesto kretanja gradom ima šaranje po policama vlastitih zbirki i kolekcija te prepuštenost nasumce biranim sadržajima nepregledne multimedijalne ponude. Drugim riječima, klikanje, listanje, preslušavanje i zapping ekvivalenti su klasičnom hodu/kretanju, a gustoća i arhitektura katedrale kulture ekvivalentna je svojoj opredmećenosti u strukturi i kulturno-civilizacijskom značaju grada. „Na flâneura vreva ulice i mnoštvo ljudi djeluje stimulativno jer sadrže potencijal za kognitivne senzacije, za osjetilni nemir i novo iskustvo" sažima Nemec (2010: 75), a istim reakcijama svjedočimo kada 
Pintarićevi ili Prtenjačini likovi poslušaju Wilca, Spiritualized, pročitaju Houellebeqa ili ih zamrzne intervju Jacksona Pollocka.

Nije stvar samo u tome da Matoš isključuje realne prostorne dimenzije kao uvjet realizacije flanerističke svrhe i smatra je isključivo duhovnim kretanjem, neovisnom o fizičkoj dimenziji, pa kaže da „pjesnici i ljudi poetični (...) najviše putuju kada najmanje putuju. (...) pjesnik, ležeći sa cigaretom na svom (ili tuđem) divanu, proputuje i vidi više od Cookovog prozaičnog putnika oko svijeta. Ne putuje tko putuje, nego tko doživljuje" (Matoš 1988: 317), kao što nije ni zanemariva poruka te gotovo potpune migracije Prtenjačinih i Pintarićevih likova iz omrznutoga realnog u utješni virtualni prostor flaniranja, nego je stvar i u tome da razlučujemo flanerističko tijelo od flanerističkog oka.

Tijelo se ne mora kretati da bi oko flaniralo. Jedan dan u svom životu, nakon što smo taj dan mi čitatelji ispratili kroz iscrpno opisane epizode koje su se skupile u tom intervalu, Prtenjačin lik rezimira upravo flanerističkim okom: „ovo je velik i lijep dan za mene: usne, cvjetovi, gležnjevi, pivo, pivo, samoća" (Prtenjača 2006: 13). Zbroj je to nasumičnih, ali snajperski zapaženih detalja koji su potakli senzacije i skupili se u estetizirani doživljaj lutanja kroz dan, potom okončan melankolijom. Ili da zaključimo rečenicom K. Pintarića kada komentira činjenicu da on i njegova partnerica nisu skloni izlascima: „to još uvijek ne znači da je čovjek mrtav” (Pintarić 2005: 33).

\section{Literatura}

Bauman Z., 2011, Tekuća modernost, prev. M. Gregov, Zagreb.

Benjamin W., 1986, Estetički ogledi, prev. T. Stamać, S. Knežević, Zagreb.

Grlić D., 1984, Misaona avantura Waltera Benjamina, Zagreb.

Karakaš D., 2004, Kako sam ušao u Europu, Zagreb.

Karakaš D., 2009, Sjajno mjesto za nesreću, Zagreb.

Kolanović M., 2008, Što je urbano u urbanoj prozi?, „Umjetnost riječi” br. 1-2, Zagreb, str. 69-89.

Krleža M., 2013, Djetinjstvo u Agramu. Davni dani, Zagreb.

Matoš A.G., 1988, Misli i pogledi, ur. M. Ujević, D. Jelčić, Zagreb.

Močnik R., 1999, Koliko fašizma?, Zagreb.

Nemec K., 2010, Čitanje grada. Urbano iskustvo u hrvatskoj književnosti, Zagreb.

Oraić Tolić D., 2005, Muška moderna i ženska postmoderna, Zagreb. 
Pintarić K., 2005, Ljubav je sve, Zagreb.

Pintarić K., 2008, U tvom zagrljaju zaboravljam svako pretrpljeno zlo, Zagreb.

Popović E., 1987, Ponoćni boogie, Zagreb.

Popović E., 2011, Lomljenje vjetra, Zagreb.

Prtenjača I., 2006, Dobro je, lijepo je, Zagreb. 